\title{
CES
}

COOPERATIVISMO E ECONOMÍA SOCIAL

Núm. 43 (2020-2021), páxs. 37-56

ISSN: 2660-6348

\section{A ECONOMIA SOCIAL E SOLIDÁRIA E O DEBATE DOS CONCEITOS MAXIMALISTA E MINIMALISTA}

\author{
THE SOCIAL AND SOLIDARITY ECONOMY AND THE \\ DEBATE OF MAXIMALIST AND MINIMALIST CONCEPTS
}

\author{
Daniel Francisco Nagao Menezes* \\ Clodoaldo Silva da Anunciação** \\ GeovÂnia Silva de Sousa***
}

Recepción: 30/06/2021 - Aceptación: 17/10/2021

\footnotetext{
* Graduação em Direito (PUC-Campinas), Especializações em Direito Constitucional e Direito Processual Civil (PUC-Campinas), em Didática e Prática Pedagógica no Ensino Superior (Centro Universitário Padre Anchieta), Mestre e Doutor em Direito Político e Econômico (Universidade Presbiteriana Mackenzie), Pós-Doutor em Direito (USP). Pós-Doutor em Economia (UNESP-Araraquara). Professor do Programa de Pós-Graduação em Direito Político e Econômico da Faculdade de Direito da Universidade Presbiteriana Mackenzie. Professor Colaborador da Maestría em Economía Social da Universidad Autónoma de Guerrero (Acapulco, México). Membro do CIRIEC-Brasil. E-mail: nagao. menezes@gmail.com.

** Doutor em Direito pela Université Paris 1 Panthéon - Sorbonne em cotutela e dupla diplomação com a Universidade de São Paulo (USP) (2016). Possui mestrado em Direito pela Universidade Federal da Bahia (2006). Professor Adjunto na Universidade Estadual de Santa Cruz (UESC), Promotor de Justiça no Estado da Bahia. E-mail: csanunciacao@uesc.br.

*** Doutora em Economia Aplicada pela Universidade Federal de Viçosa (UFV). Possui mestrado em Desenvolvimento Regional e meio ambiente pela Universidade Estadual de Santa Cruz (UESC) e graduação em Economia também pela Universidade Estadual de Santa Cruz (UESC). E-mail: gsilvadsousa@gmail.com.
} 


\title{
RESUMO
}

A construção do conceito e significado da Economia Social e Solidária na América Latina é um espaço em construção, permitindo a existência de várias interpretações. $\mathrm{O}$ artigo explora as duas principais alternativas (conceito maximalista e conceito minimalista) e, com base nestas descrições, analisa quatro temas centrais na agenda de pesquisa: o papel do mercado na Economia Social e Solidária; a relação entre solidariedade sistêmica e solidariedade de proximidade; construir cooperação e confiança; e equidade de gênero. O método de pesquisa é o hipotético dedutivo com uso da revisão bibliográfica.

Palavras chave: Comportamento econômico; Economia Social e Solidária; Solidariedade.

\begin{abstract}
The construction of the concept and meaning of Social and Solidarity Economy in Latin America is a space under construction, allowing for the existence of several interpretations. The article explores the two main alternatives (maximalist and minimalist concept) and, based on these descriptions, analyzes four central themes in the research agenda: the role of the market in the Social and Solidarity Economy; the relationship between systemic solidarity and proximity solidarity; build cooperation and trust; and gender equity. The research method is the hypothetical deductive with the use of bibliographic review.
\end{abstract}

KEYWORDS: Economic behavior; Social and Solidarity Economy; Solidarity. 
SUMÁRIO: 1. INTRODUÇÃO. 2. A DEFINIÇÃO MAXIMALISTA. 3. OS DESAFIOS DA AGENDA DE PESQUISA. 4. CONCLUSÃO. 5. REFERÊNCIAS

SUMMARY: 1. INTRODUCTION. 2. THE MAXIMAL DEFINITION. 3. THE CHALLENGES OF THE RESEARCH AGENDA. 4. CONCLUSION. 5. REFERENCES

\section{INTRODUÇÃO}

Economia Social e Solidária é um campo emergente de investigação
que procura compreender as várias formas de organização econômica:
cooperativas, associações de produção e comercialização, mútuas, fundações e organizações sem fins lucrativos, sociedades ou empresas sem fins lucrativos ou sem fins lucrativos, rendimentos grupos de geração, grupos de produção e comercialização ecológica, comunidades produtivas indígenas e camponesas, entre outros. Essas formas de organização alternativas, tanto à empresa privada orientada para a maximização dos lucros quanto à lógica estatal, foram ganhando denominativos nas diversas regiões: terceiro setor, empresa social e empreendedorismo solidário. Do mesmo modo, vários conceitos foram colocados sobre a mesa: economia social, economia solidária, economia do trabalho e economia para a vida. Embora esses conceitos estejam inscritos em diferentes referenciais teóricos e sejam objeto de controvérsias teóricas e políticas, eles abriram um novo campo analítico para a compreensão da economia ${ }^{1}$.

Na América Latina, as fontes históricas do conceito de Economia Social e Solidária (ESS) encontram-se nas experiências de cooperativismo e associativismo da região, enquanto as fontes mais recentes localizam-se a partir dos anos oitenta,

\footnotetext{
CATTANI, A. D.; LAVILLE, J.-L.; GAIGER, L. I.; HESPANHA P. Dicionário Internacional Outra Economia. Coimbra: Almedina, 2009. CORAGGIO, J. L. "La economía social y solidaria: hacia la búsqueda de posibles convergencias con el Vivir Bien". in Farah, I.; Tejerina, V. (orgs.) Vivir Bien: Infancia, género y economía. Entre la teoría y la práctica. La Paz: Plural Editores, 2013, p 215-256. DEFOURNY, J. Y; NYSSENS, M. El enfoque emes de empresa social desde una perspectiva comparada. CIRIEC España - Revista de Economía Pública, Social y Cooperativa, (75)7, 2012. HILLENKAMP, I.; LAVILLE, J.-L. et al. Theory of the social enterprise and pluralism. The model of solidarity enterprise. Artigo apresentado no ICSEM MEETING. Bruxelas, 2013. QUIJANO, O. A. "The Marginal Role of the Economy and the Marginal Labor Force". Economy and Society, 3(4), 393-428, 1974. RAZETO, L. Los caminos de la economía de solidaridad. Buenos Aires: Lumen-Humanitas, 1996. SINGER, P. "Economía solidaria. Un modo de producción y distribución". in Coraggio, J-L (org.) La Economía Social desde la periferia. Contribuciones latinoamericanas. Buenos Aires: Altamira, 2007, p. 59-78. VEGA UGALDE, S. "La economía solidaria en el Ecuador de la Revolución ciudadana: Certezas e interrogantes". Opción Socialista, 3, 50-51, 2014. WANDERLEY, F. Desafíos teóricos y políticos de la economía social y solidaria. Lectura desde América Latina. Bogotá: CIDES-UMSA, 2015.
} 
na expansão da economia popular, as ações da Igreja Católica, ONG e cooperação internacional que visam apoiar iniciativas de geração de renda implantadas por trabalhadores não assalariados no contexto das políticas neoliberais. Um dos primeiros a formular o conceito de economia popular solidária foi o chileno Luis Razeto na década de 1980.

A mudança interpretativa nas iniciativas populares foi radical nas últimas décadas. Do prisma da economia informal, passou ao prisma da Economia Social e Solidária. Uma das diferenças mais importantes entre essas duas perspectivas está no papel que essas iniciativas desempenham na sociedade e na economia. Do prisma da economia informal, essas unidades econômicas dirigidas pelos trabalhadores foram interpretadas como um produto da incapacidade do desenvolvimento capitalista na região de gerar empregos assalariados para uma população urbana em rápido crescimento. A população deste setor estaria sujeita a uma situação de pobreza e estagnação devido à sua suposta incapacidade de produzir excedentes. Estabeleceu-se uma associação quase direta entre pobreza e setor informal, conceito muito próximo ao de "marginalidade" proposto por Quijano² e de "massa marginal" por Nun ${ }^{3}$ sob o paradigma marxista do desenvolvimento capitalista desigual e gerador de um exército de trabalho de reserva.

Do prisma da Economia Social e Solidária na América Latina, inspirado também e em grande medida no referencial teórico crítico, as unidades autogestionárias pelos trabalhadores foram reinterpretadas como experiências não capitalistas cujo desenvolvimento não só é viável, mas também contém um potencial emancipatório e contra-hegemônico. Essas experiências apontariam para um possível modo de produção alternativo ao capitalismo. Seguindo o argumento, sua racionalidade específica - subsistência, produção de valor de uso, reprodução simples ou ampliada - deixa de ser entendida como "pré-capitalista" para ser "anticapitalista". Essa mudança interpretativa é observada em Quijano ${ }^{4}$ que aponta que esses atores deixam de ser vítimas do desenvolvimento para se tornarem os novos protagonistas da emancipação social.

Nessa tradição, a perspectiva crítica e emancipatória da Economia Social e Solidária articula dois registros — político e acadêmico—, repensando a relação entre universidade e política e estabelecendo novos desafios para a profissão acadêmica e seu vínculo com os destinos da sociedade na qual está imerso. Esses desafios são multidimensionais e complexos. Especificamente, há o desafio de articular dois compromissos: a "objetividade" do conhecimento sui generis das ciências sociais

\footnotetext{
2 QUIJANO, O. A. The Marginal... op. cit.

3 NUN, J. "Superpoblación relativa, ejército industrial de reserva y masa marginal". Revista latinoamericana de Sociología, (5)2, 1969.

4 QUIJANO, O. A. "Sistemas alternativos de produção?” in Santos, B. S. (org.). Produzir para viver. Os caminhos da produção não capitalista. Porto: Afrontamento, 2003, p. 407-435
} 
e o compromisso político com as lutas populares e emancipatórias. Ou seja, o desafio de inter-relacionar as esferas acadêmica e política e, ao mesmo tempo, não subordinar uma à outra. Nesse sentido, a discussão sobre a economia social e solidária na América Latina assumiu um caráter público no sentido proposto por Burawoy $^{5}$, ou seja, uma perspectiva voltada para diferentes públicos e não apenas para o círculo de profissionais da Academia. Nesse sentido, clama por um papel mais ativo das ciências sociais nas discussões sobre questões políticas e políticas públicas, em um diálogo mais próximo com ativismos políticos e movimentos sociais em defesa da sociedade civil assediada pela intrusão do mercado.

Duas alternativas epistemológicas são percebidas na discussão acadêmica sobre Economia Social e Solidária. Por um lado, há a proposta de não apagar as fronteiras entre a esfera política e a esfera acadêmica como discursos distintos, apesar de sua estreita relação, e, por outro lado, há a proposta de questionar a separação entre realidade e utopia em análise empírica. A primeira estabelece a concepção minimalista das unidades econômicas que compõem a economia social e solidária a partir de critérios sobre sua forma de organização, como, por exemplo, propriedade coletiva, autogestão democrática e articulação de objetivos sociais e econômicos. Essa definição se aproxima do conceito de empresa social de Defourny e Nyssens ${ }^{6}$. A segunda fundamenta o conceito maximalista de unidades econômicas que, além dos critérios de sua forma organizacional do conceito minimalista, agrega valores que norteiam as práticas dos atores como igualdade, solidariedade e proteção ambiental, ou seja, em uma racionalidade solidária. Essa definição se aproxima do conceito de empresa solidária de Hillenkamp e Laville ${ }^{7}$.

Este texto propõe uma leitura crítica das tensões teóricas na construção do objeto de estudo e, a partir disso, analisa quatro temas emergentes na atual agenda de pesquisa em Economia Social e Solidária na América Latina. Argumenta-se a favor do conceito minimalista e de uma perspectiva relacional do comportamento econômico e aborda os seguintes tópicos: o conceito de mercado; a relação entre solidariedade sistêmica e solidariedade de proximidade; construir cooperação e confiança; e igualdade de gênero.

\section{A DEFINIÇÃO MAXIMALISTA}

A definição maximalista de Economia Solidária é explicitada na introdução da importante obra coletiva Dicionário Internacional Outra Economia ${ }^{8}$ (2009):

\footnotetext{
BURAWOY, M. "2004 Presidential address For Public Sociology”. American Sociological Review, (70), 4-28, 2005.

6 DEFOURNY, J.; NYSSENS, M. El enfoque ... op. cit.

7 HILLENKAMP, I.; LAVILLE, J.-L. Theory of ... op. cit.

8 LAVILLE, J.-L.; GAIGER, L. I. "Economia Solidaria”. in Cattani, A. D.; Laville, J-L.; Gaiger L.

I.; Hespanha, P. (orgs.). Dicionário Internacional Outra Economia. Coimbra: Almedina, 2009, p. 162.
} 
A construção desta obra está em sintonia com os ideais e realizações objetivas de outra economia, que se apresenta como alternativa material e humana superior à economia capitalista. Denominadas por termos como economia solidária, economia do trabalho, novo cooperativismo, empresas autogestionárias e outros, essas formas correspondem a conquistas inovadoras, associadas a novos valores e princípios que se opõem a práticas predatórias de exclusão social e ambiental.

Em outra publicação importante, Produzindo para Viver - Os caminhos da produção não capitalista ${ }^{9}$, Boaventura de Sousa Santos define o objeto de estudo da Economia Social e Solidária da seguinte forma:

O que é necessário, então, é focalizar simultaneamente a atenção na viabilidade e potencial emancipatório das múltiplas alternativas que foram formuladas e praticadas em todo o mundo que representam formas de organização econômica baseadas na igualdade, solidariedade e proteção do meio ambiente.

A partir da definição maximalista de ESS, a agenda de pesquisa orienta-se para a busca de experiências em que o princípio da solidariedade democrática atue e atue nas práticas econômicas. Esta proposta atribui ao objeto de estudo —os atores da economia popular e solidária — um projeto político emancipatório e contra-hegemônico baseado na existência —ou potencial— de sociabilidades anticapitalistas, cujo eixo central é a solidariedade. Nessa perspectiva, uma das questões centrais que norteiam a discussão latino-americana da Economia Popular e Solidária refere-se à viabilidade dessas formas econômicas alternativas constituírem uma proposta política de uma nova ordem não capitalista.

A tarefa do pensamento e das práticas emancipatórias é ampliar o espectro do possível, por meio da experimentação e reflexão sobre alternativas que representem formas mais justas de sociedade. Olhando para além do que existe, tais formas de pensamento e prática questionam a separação entre realidade e utopia, e formulam alternativas que são utópicas o suficiente para desafiar o status quo e são reais o suficiente para não serem facilmente descartáveis porque são inviáveis.

O conceito maximalista de Economia Social e Solidária tem, sim, raízes em movimentos de cidadãos, pesquisadores, produtores e consumidores comprometidos com os princípios da igualdade, solidariedade, justiça e proteção do meio ambiente em diversos países, e constitui um poderoso instrumento político de disputa, na esfera pública, uma nova escala de valores que permite avaliar a con-

9 SANTOS, B. S. Produzir para viver. Os caminhos da produção não capitalista. Porto: Afrontamento, 2003, p. 17. 
tribuição das diversas formas de atividade econômica para o desenvolvimento das sociedades para além dos parâmetros de mercado. Nesse sentido, o conceito maximalista de Economia Social e Solidária no campo político torna-se um parâmetro prescritivo com critérios claros para orientar a reestruturação das organizações econômicas e ações políticas para uma ordem mais justa, solidária, inclusiva e sustentável. Da mesma forma, torna visíveis os benefícios sociais e econômicos de outras modalidades organizacionais baseadas na autogestão coletiva.

\subsection{Os problemas da definição maximalista}

Apesar das vantagens do conceito maximalista no campo político mencionadas na seção anterior, identificamos problemas da adoção do conceito maximalista na análise acadêmica. Verificamos que a transferência, não mediada, dos ideais do movimento político para o objeto de estudo contém problemas para avançar no entendimento da dinâmica social e econômica do setor da economia formado por organizações coletivas, administradas por trabalhadores-membros e orientado para objetivos econômicos - a geração de excedentes - em coordenação com fins sociais.

O primeiro problema que encontramos com o conceito maximalista de ensaio na análise acadêmica refere-se à relação entre economia popular e economia solidária. O conceito maximalista de economia solidária conduziu a novas definições de economia popular que incluem fortes pressupostos sobre os significados compartilhados pelos atores e os princípios estruturantes das iniciativas econômicas. Se antes a economia popular era entendida como um conjunto de atividades econômicas e práticas sociais desenvolvidas por sujeitos pertencentes às classes trabalhadoras, por meio do uso da própria força de trabalho e da mobilização de recursos escassos, agora, à luz da concepção maximalista de economia solidária , a economia popular passa a ser definida como "uma forma de produzir, distribuir e consumir bens e serviços que transcende a obtenção de ganhos monetários, estando intimamente ligada à reprodução da vida (e não do capital) e tendo por horizonte a satisfação dos valores de uso e da valorização do trabalho e do ser humano" 10 .

Como visto na citação anterior, este novo conceito de economia popular, do prisma do conceito maximalista de Economia Social e Solidária, parte do pressuposto de que o comportamento econômico na economia popular possui uma "racionalidade" específica: a satisfação dos valores de uso e a valorização do trabalho e do ser humano, como uma ética de vida que os atores seguiriam.

10 ICAZA, A. M. S.; TIRIBA, L. (2009). “Economia popular”. in Cattani, A. D.; Laville, J-L.; Gaiger L. I.; Hespanha, P. (orgs.). Dicionário Internacional Outra Economia. Coimbra: Almedina, 2009, p. 150. 
Um segundo pressuposto, intimamente relacionado ao anterior, é a ideia de que as práticas defensivas de sobrevivência que caracterizam a economia popular se transformarão, quase como uma "evolução natural", em um projeto de sociedade cooperativa e solidária. Nós exemplificamos essa suposição reproduzindo a seguinte citação ${ }^{11}$ :

Muitos autores e ativistas seguem a perspectiva de Luís Razeto, referindo-se a uma "economia popular de solidariedade" ou "economia popular solidária", aludindo a experiências que se caracterizam explicitamente como formas coletivas de organização e que têm a solidariedade como projeto político. Nesse sentido, segundo Razeto, o potencial da economia popular consistiria na viabilização de que, aos poucos, essas estratégias defensivas de sobrevivência se tornassem uma opção social, econômica e política. Nessa perspectiva, a economia solidária é percebida como um horizonte da economia popular, permitindo, assim, avançar um projeto de sociedade baseado na solidariedade e na cooperação.

A adoção do pressuposto de um comportamento econômico unívoco e coerente do conceito maximalista de economia popular, social e solidária encontra sérios problemas de adequação empírica. Existem muitas evidências sobre o hibridismo e a diversidade das orientações do comportamento econômico em todos os setores e grupos, inclusive aqueles que atendem aos requisitos do conceito minimalista: a) pertencem a setores desfavorecidos e com poucos recursos; b) se organizam coletivamente para gerar renda, e; c) combinam fins sociais e econômicos. Muitos estudos mostram a ausência de um projeto político emancipatório, com igualdade de gênero e comprometido com a proteção do meio ambiente neste setor. Com efeito, o universo da Economia Social e Solidária é muito diverso nos países latino-americanos e, em grande medida, é constituído por trabalhadores com recursos limitados e em situação de precariedade laboral e social que não têm necessariamente compromissos políticos para transformar a economia, ordem econômica e menos com igualdade de gênero e proteção ambiental.

A alternativa ao conceito essencialista de comportamento econômico é o conceito de comportamento econômico em construção contínua a partir da perspectiva relacional das identidades dos atores, na medida em que estas não necessariamente guardam coerência em todas as áreas e circunstâncias de suas vidas ${ }^{12}$.

\footnotetext{
11 ICAZA, A. M. S.; TIRIBA, L. Economia ... op. cit. p. 154.

12 BOURDIEU, P. Las estructuras sociales de la economía. Buenos Aires: Manantial, 2000. BOURDIEU, P. "Principles of Economic Anthropology". In Smelser, N.; Swedberg, R. (orgs.). The Handbook of Economic Sociology. New York: Sage, 2005, pp. 75-89. WHITE, H. "Social Networks can Resolve Actor Paradoxes in Economics and in Psychology". Journal of Institutional and Theoretical Economics,
} 
Ao contrário, os comportamentos dependem das interações em que se encontram, uma vez que as expectativas mútuas são criadas em processos contínuos que incluem estruturas cognitivas, modelos de associação, sentidos de pertencimento e de lutas ou disputas por controle e poder. O relacionismo metodológico ${ }^{13}$ das ciências sociais entende a cultura como indissociável da prática e, portanto, como algo instável e em contínua transformação. Ou seja, os horizontes dos atores só podem ser identificados por pesquisas empíricas voltadas para a compreensão dos processos por meio dos quais os comportamentos econômicos vêm a se instituir.

Um segundo problema do conceito maximalista de unidades econômicas solidárias é o pressuposto da presença do que Razeto ${ }^{14}$ definiu como Fator C: companheirismo, cooperação, comunidade, compartilhamento, comunhão, coletividade, carisma, colaboração. O pressuposto da presença do Fator C nas unidades econômicas solidárias limita a análise dos problemas teóricos e políticos da ação coletiva, da cooperação e do associativismo nas iniciativas promovidas pelos trabalhadores. Em outras palavras, a definição maximalista do objeto de estudo contribui para não problematizar a construção, manutenção e projeção da cooperação e da associatividade em diferentes níveis e em escala mais ampla nas organizações coletivas. Nesse quadro, é possível notar que o problema da ação coletiva e da associatividade não foi abordado em profundidade nesta literatura e, consequentemente, um conjunto de questões permanece à margem, como, por exemplo, por que a associatividade e a cooperação são difíceis. para construir na economia popular, social e solidária na América Latina, ou porque são mais a exceção do que a regra.

Um terceiro problema detectado no conceito maximalista, que deriva dos anteriores, é a orientação da análise acadêmica para a busca do sujeito histórico portador de uma nova ética e racionalidade, para torná-lo visível e potencializar suas experiências no mar conturbado da economia popular, sob a suposição de que esses assuntos ainda não se manifestaram devido à opressão de mundos hostis. Essa orientação corre o risco de sobrepor o discurso político ao discurso acadêmico e, consequentemente, orientar a pesquisa a buscar o sujeito do projeto político ao invés de compreender a complexidade das práticas e dinâmicas dos atores sociais e econômicos - organizados coletivamente sob modelos de self -gerência - por meio

151(1), 58-74, 1995. SOMERS, M. "Citizenship and the Place of the Public Sphere: Law, Community, and Political Culture in the Transition to Democracy". Social Science History, 16(4), 1993.

13 O relacionismo metodológico assume que a explicação dos fenômenos sociais deve ser fundamentada nos processos concretos de interação social e agência com reflexividade. Ele se afasta do atomismo metodológico, considerando que as relações sociais e os padrões agregados dessas relações constituem fatores explicativos. Da mesma forma, ele se afasta do holismo metodológico, tomando interações entre os indivíduos, às intenções e significados dados às suas ações como parte constitutiva da explicação.

14 RAZETO, L. Los caminos ... op. cit. 
de análise empírica. Essa busca pelo sujeito histórico e pelas experiências que contêm as alternativas à economia capitalista neoliberal é observada na seguinte citação ${ }^{15}$ :

No início do século XXI, a aceleração dos movimentos de capitais para longe dos compromissos com a comunidade, esbarrou na diminuição da satisfação das necessidades humanas e na persistência da pobreza em grandes regiões do planeta. Encontrar as respostas para essas mudanças na economia e na política é uma tarefa fundamental. A reconstrução das condições objetivas e subjetivas de transformação social exige uma atenção redobrada às iniciativas que contenham, ainda em germe e em pequena escala, a capacidade de se estabelecerem em outras formas de vida, na medida em que estão imbuídas do valor da justiça, de um ethos redistributivo e de um desejo de humanização. Em particular, é importante valorizar as experiências que nascem da auto-organização, que defendem os direitos fundamentais do trabalho, e que apostam na associação e nas soluções coletivas, formando um acúmulo de experiências e convicções morais e intelectuais essenciais à construção dos novos rumos para a sociedade.

No entanto, o perigo de penetração do discurso político no discurso analítico foi percebido por vários desses mesmos pesquisadores, como, por exemplo, Gaiger ${ }^{16}$ :

O conceito de empreendedorismo econômico solidário está exposto aos mesmos riscos de formulações sobre determinadas categorias da práxis. Nesses casos, o fato de se relacionar com as práticas e de se posicionar de acordo com os propósitos de intervenção na realidade traz problemas de uma interpenetração descontrolada entre o discurso analítico e o discurso político e pragmático. (...) No nível concreto, esses problemas se manifestam na reificação do conceito e em sua assimilação normativa. Ao despertar entusiasmo e otimismo, sua clareza nos leva a considerála um reflexo apurado da realidade, apesar (...) do impasse de encobrir motivações e iniciativas de origens e naturezas diversas.

Nesse sentido, Gaiger destaca o desafio epistemológico e teórico da perspectiva teórica da economia solidária, embora não identifique esse risco na adoção do

15 LAVILLE, J.-L.; GAIGER, L. I. Economia ... op. cit. p. 162

16 GAIGER, L. I. "Empreendimento Econômico Solidário". in Cattani, A. D.; Laville, J-L.; Gaiger L.

I.; Hespanha, P. (orgs.). Dicionário Internacional Outra Economia. Coimbra: Almedina, 2009, p. 185. 
conceito maximalista na análise acadêmica. Coraggio ${ }^{17}$ (2013) também apontou problemas no conceito maximalista na análise acadêmica, propondo-se a considerar diferentes níveis de análise nas práticas e instituição das organizações econômicas populares, que apontam um caminho a seguir para avançar em direção aos valores e princípios de solidariedade e igualdade e/ou proteção ambiental. Este autor destaca que, em seu surgimento ou em um primeiro nível, o espaço da economia popular atua no nível microeconômico e se caracteriza por um conjunto de práticas de inserção que visam o alívio da pobreza e da exclusão de grupos de pessoas ou famílias excluídas do mercado de trabalho em sentido amplo. Ou seja, a princípio sua lógica seria pautada pela urgência ou pela subsistência sem se desvincular da cultura do mercado e do interesse individual; seus vínculos com seus ambientes mediatos e mais amplos seriam mediados pela assistência, pela solidariedade filantrópica e/ou pela busca de gratificações particulares.

A possibilidade de "dar um salto" para a Economia Solidária —ou segundo nível de organização— dependerá, na opinião de Coraggio ${ }^{18}$, de se assumir que a eficácia social e a sustentabilidade das iniciativas econômicas promovidas só se encontrarão em redes solidárias competitivas, mas não meramente econômicas mas com complementaridades sociais e políticas, com condições para a sua formação como sujeitos coletivos - associações locais, setores ou redes transversais de comércio justo - constituídas num "setor orgânico" ou em um todo interdependente dessas solidariedades. Por fim, é necessário transcender a um terceiro nível que vai além da constituição de um subsistema de essências dentro de uma economia mista, que pode ser chamada de "outra economia" e que avança para o desenvolvimento de economias integradas na sociedade a partir de relações de solidariedade, de justiça, de igualdade, guiadas pelo critério comum da reprodução ampliada da vida. Essa possibilidade requer a articulação do plano econômico com o cultural e político.

Sem tentar abolir os demais princípios e seus padrões institucionais - os negócios capitalistas, por exemplo - buscar-se-ia neste nível limitar suas ações e sua cultura, contestando sua hegemonia. Essas discussões indicam que na América Latina há uma longa história da Economia Social e Solidária a partir do critério minimalista das organizações econômicas que a compõem - propriedade e gestão coletiva, relações de trabalho entre sócios e critérios de distribuição de excedentes distintos dos empresa do setor privado ou público, solidariedade de proximidade e finalidades sociais e econômicas -, enquanto a Economia Social e Solidária do critério maximalista - racionalidade orientada para o bem comum, equidade, sustentabilidade ambiental e alicerçada em níveis avançados de confiança, colaboração e associatividade, ainda é um projeto político em construção. Apesar dessas

17 CORAgGiO, J. L. La economia ... op. cit., p 232.

18 CORAGGiO, J. L. La economia ... op. cit., p 234. 
evidências, ainda existem ambivalências conceituais sobre o campo de pesquisa da economia social e solidária na região.

Nesse sentido, defende-se que, no estudo acadêmico, a proposta maximalista do objeto de estudo dificulta a análise das relações sociais que estruturam experiências concretas em formas organizacionais distintas daquelas do setor privado tradicional e do setor público, em toda sua complexidade interna, em seu ambiente imediato e mais amplo. Além disso, exclui do estudo as organizações populares que não compartilham os valores e princípios da igualdade, solidariedade e proteção do meio ambiente, embora apresentem formas organizacionais baseadas no trabalho coletivo, autogestão, solidariedade de proximidade e objetivos sociais.

\section{Os DESAFIOS DA AGENDA DE PESQUiSA}

A opção pelo conceito minimalista das organizações que integram a Economia Social e Solidária - propriedade e gestão coletiva, relações de trabalho entre sócios e critérios de distribuição de sobras distintas da empresa privada ou do setor público, solidariedade de proximidade e objetivos sociais e econômicos - e devido ao relacionismo metodológico sobre o comportamento econômico, é possível avançar na análise de quatro temas emergentes na agenda de pesquisa. Esses tópicos são: o conceito e o papel do mecanismo de mercado na outra economia; a relação entre solidariedade sistêmica e solidariedade de proximidade; cooperação, associatividade e ação coletiva; e equidade de gênero. A discussão que se segue busca contribuir para essa agenda por meio do diálogo com outras instâncias analíticas que exploraram problemas relacionados.

\subsection{O conceito de Mercado}

Um dos temas ainda insuficientemente abordado pela literatura sobre Economia Social e Solidária é aquele que se referia ao conceito de mercado e sua relação com os demais princípios e padrões de integração econômica. $\mathrm{O}$ conceito de mercado, nesta literatura, ainda é altamente dependente da teoria econômica neoclássica que o vincula a um tipo de institucionalidade de mercado livre e autorregulada. Essa definição fecha a possibilidade de compreender o mercado como processo e espaço de relações socialmente instituído e, portanto, passível de ser regido por regras e regulamentos plurais. Também torna difícil entender a dinâmica híbrida de cooperação e competição que articula as relações econômicas.

A principal fonte de inspiração para a literatura da Economia Social e Solidária encontra-se na obra de Karl Polanyi (1886-1964). Este autor articulou uma teoria sobre os princípios estruturantes da produção e distribuição de bens e serviços 
para a satisfação das necessidades humanas ao longo da história. Karl Polanyi ${ }^{19}$ identificou princípios de integração e padrões institucionais ordens econômicas a partir do estudo das experiências sociais em perspectiva histórica, os mesmos que são considerados tipos ideais. Existem quatro princípios e seus respectivos padrões identificados: redistribuição, centralidade, troca com competição, mercado, reciprocidade, assimetria, subsistência, administração doméstica.

A nova sociologia econômica tem muito a contribuir aqui. A partir do conceito de mercado como um processo socialmente instituído, a nova sociologia econômica desenvolveu estudos empíricos sobre o funcionamento dos mercados como estruturas sociais. Em contraposição ao conceito neoclássico de mercado, entendido como mecanismo abstrato de definição de preço e resultado lógico da propensão universal do homo economicus atomizado e utilitário, os estudos sociológicos mostram o mercado como mecanismo de coordenação sustentado por pessoal e impessoal, relações entre atores, práticas sociais que compartilham estruturas cognitivas e agem sob regras formais e informais ${ }^{20}$.

A concepção sociológica de mercado permite compreender como princípios e instituições plurais se relacionam ou se articulam no ordenamento econômico das sociedades de mercado, substituindo a ideia de sociedades de mercado. Também permite avançar na discussão sobre o caráter político e cultural da ordem econômica, onde o lugar e a abrangência do mercado são o resultado de decisões e dinâmicas esperadas e inesperadas, e não apenas de leis econômicas naturais que emanariam de dinâmica autônoma. Em suma, essa posição liberta a imaginação sociológica para pensar em desenvolvimentos alternativos que não requeiram a eliminação do mercado como um dos mecanismos de coordenação. Consequentemente, permite discutir como enquadrar o mercado num quadro plural de princípios e instituições e, assim, não excluir da análise os problemas enfrentados pelas economias locais, nacionais e regionais nas dinâmicas competitivas globalizadas.

19 POLANYI, K. "The economy as instituted process". in Granovetter, M. Swedberg, R. (org.). The sociology of economic life. Westview: Westview Press, 1992, p 29-52.

20 WHITE, H. Markets from networks: socioeconomic models of productions. Princeton: Princeton University Press, 2002. GRANOVETTER, M. "Economic Action and Social Structure: The Problem of Embeddedness". in Granovetter, M.; Swedberg, R. (org.). The Sociology of Economic Life. Boulder: Westview Press, 1992, p. 53-84. ABOFALIA, M. Making markets: Opportunism and restraint on Wall Street. Cambridge: Harvard University Press, 1996. BAKER, W. E. "The social structure of a national security market". American Journal of Sociology, 89(4), 775-811, 1984. BURT, R. Structural holes. The Social Structure of Competition. Cambridge: Harvard University Press, 1992. DOBBING, F. Forging Industrial Policy: The United States, Britain, and France in the Railway Age. Cambridge: Cambridge University Press, 1997. KNORR CETINA, K. "How are global market global? The architecture of a flow world". in Knorr Cetina, K. Preda, A. (orgs.). The Sociology of Financial Markets. Oxford: Oxford University Press, 2005, p. 38-61. FLIGSTEIN, N. The architecture of markets. An Economic Sociology of twenty-first-century capitalist societies. Princeton: Princenton University Press, 2001. EVANS, P. Embedded Autonomy: States and industrial transformation. Princeton: Princeton University Press, 1995. ZELIZER, V. The social meaning of money. New York: Basic Books, 1997. 


\subsection{Cooperação, Associatividade e Ação Coletiva}

A literatura sobre Economia Social e Solidária dá muita ênfase ao papel da cooperação, associação e ação coletiva e, paradoxalmente, não se aprofundou suficientemente nos desafios teóricos e empíricos que os laços entre as pessoas implicam para alcançar objetivos comuns, especialmente na esfera econômica. A importância da cooperação, associação e ação coletiva na economia tem sido amplamente estudada pela sociologia econômica e pelo institucionalismo econômico ${ }^{21}$.

Supor que este é um problema sociológico significa não naturalizar a confiança, base da cooperação; e, inversamente, partindo do pressuposto de que a confiança é uma construção social que requer reafirmação contínua ${ }^{22}$. Isso implica abandonar o pressuposto, implícito na concepção maximalista da Economia Solidária, de que a cooperação é um processo imanente de determinados grupos ou setores econômicos. E, portanto, compreender que o desafio está em superar a tentação de substituir o conceito utilitário de Homo economicus pelo de Homo economicus solidarius. Isso implica enquadrar a compreensão da construção social da cooperação, da associatividade e da ação coletiva a partir do relacionismo metodológico e do conceito minimalista de Economia Solidária. Esse posicionamento teórico direciona a atenção para a compreensão e explicação da - sempre inacabada - estruturação de expectativas, compromissos, práticas baseadas em regras, mecanismos de monitoramento e sanção em caso de não cumprimento. Esses são os fatores que sustentam o surgimento e a manutenção da cooperação ao longo do tempo.

\subsection{Solidariedade Sistêmica e Solidariedade de Proximidade}

Outro desafio na literatura sobre Economia Popular, Social e Solidária na América Latina visa aprofundar a inscrição das unidades econômicas na estrutura social, econômica e política mais ampla e, especificamente, as implicações de sua exclusão ou marginalidade na solidariedade sistêmica —Proteção e social sistemas de segurança - de seus países. Em contextos de precariedade e informalidade,

\footnotetext{
${ }^{21}$ OSTROM, E.; AHN, T. K. “Una perspectiva de capital social en las ciencias sociales: capital social y acción colectiva”. Revista Mexicana de Sociología, 65(1), 155-233, 2003. BAGNASCO, A.; SABEL, C. F. Small and médium size enterprises. London: Pinter, 1995. SARAVÍ, G. "Entre la comunidad y la autosuficiencia. Cooperación y competencia en un distrito industrial en México". Nueva Antropología, 16(55), 69-87, 1999. WANDERLEY, F. Solidarity without cooperation. Small producer networks and political identity in Bolivia. (Tese de Doutorado em Ciências Sociais). Columbia University, 2004. TURCHI, L. M.; NOROÑA, E. G. Cooperação e conflito: um estudo de caso do complexo coureiro-calçadista no Brasil. Texto de discussão n. ${ }^{\circ}$ 861. Rio de Janeiro: IPEA, 2002. AXELROD, R. La evolución de la cooperación: el dilema del prisionero y la teoría de juegos. Madrid: Alianza Editorial, 1984.

22 ZUCKER, L. G. "Production of Trust: Institutional sources of economic structure, 1840-1920". Research in Organizational Behavior, 8, 1986.
} 
como na América Latina, os atores da economia social e solidária enfrentam inseguranças básicas para a reprodução de suas vidas que não podem ser resolvidas pela solidariedade de proximidade - modalidades de proteção baseadas em vínculos pessoais de sociabilidade primários-

A discussão na região distancia-se da discussão europeia de ESS porque esta se inscreve em contextos do Estado de Bem-Estar Social construído no pós-guerra que, embora em crise, ainda mantém um nível de proteção social muito superior ao de outros continentes. É neste contexto que se propõe que a solidariedade sistémica, alicerçada no conceito de cidadania social e estabelecida pelo princípio da redistribuição através das políticas sociais, já não é suficiente para enfrentar a exclusão, a anomia e o individualismo. Para tanto, defende novas práticas, princípios e espaços institucionais que operem em prol da criação e manutenção de vínculos pessoais na promoção de bens comuns, na formação de identidades sociais e na ação coletiva. A discussão europeia propõe as alternativas e complementos entre os instrumentos de política social em países que já avançaram na institucionalização dos direitos sociais, mas que se perderam na sociabilidade primária ${ }^{23}$.

Em nossos países não é possível privilegiar este último com base no pressuposto de que a solidariedade sistêmica já está estabelecida ou que pode ser substituída pela solidariedade de proximidade. Assim, um horizonte político e um quadro analítico diferentes impõem-se à abordagem europeia sobre a relação entre a solidariedade sistémica e a solidariedade de proximidade.

\subsection{Equidade de gênero}

Um tema emergente na literatura sobre ESS é aquele que se refere à inclusão da igualdade de gênero em um diálogo com a economia feminista $(\mathrm{EF})^{24}$. Existem muitas afinidades entre as duas abordagens. A primeira é a convergência da crítica

${ }^{23}$ LAVILLE, J.-L.; GAIGER, L. I. Economia ... op. cit.

${ }^{24}$ Sobre a literatura internacional de Economia Feminista, conferir: AGUIRRE, R. "Trabajar y tener hijos: insumos para repensar las responsabilidades familiares y sociales". in M. L. Gutiérrez, M. L. (org.) Género, familias y trabajo: rupturas y continuidades. Desafíos para la investigación política. Buenos Aires: Clacso, 2007, pp. 99-135. ANDERSEN, J. "El sueño de la casa sin cocina". in Guzmán, V.; Portocarrero, P.; Vargas, V. (org.). Una nueva lectura: género en el desarrollo. Lima: Flora Tristán, 1991, p. 159-190. ARRIAGADA, I. Futuro de las familias y desafíos para las políticas. Santiago: CEPAL, 2008. BENERÍA, L.; ROLDÁN, M. The crossroads of class and gender. Industrial homework, subcontracting and household dynamics in Mexico City. Chicago: University of Chicago Press, 1987. BLAU, F. D.; FERBER, M. A.; WINKLER, A. E. The Economics of momen, men and work. New Jersey: Prentice Hall, 1986. BORDERÍAS, C.; CARRASCO C. Las mujeres y el trabajo. Rupturas conceptuales. Madrid: Economía Crítica, 1994. BOSERUP, E. Woman's Role in Economic Development. New York: Allen \& Unwin, 1970. JELIN, E. Pan y afectos. La transformación de las famílias. Cidade do México: Unam, 2000. KABEER, N. Realidades trastocadas. Las jerarquías de género en el pensamiento del desarrollo. Cidade do México: Paidós, 1998. PAUTASSI, L.; RICO, M. N. "Licencias para el cuidado infantil. Derechos de hijos, padres y madres". Revista Desafíos. Cuidado 
aos pressupostos da economia neoclássica. Uma segunda está associada ao alívio do princípio da subsistência e da instituição do lar em ambas as propostas. Um terceiro tem a ver com o princípio da equidade que sustenta tanto o movimento ESS quanto o movimento $\mathrm{EF}^{25}$.

Apesar desses fatores comuns, uma das principais dificuldades desse diálogo reside na divergência das perspectivas epistemológicas que norteiam a construção do objeto de estudo da ESS e da EF. A economia feminista avançou muito na análise das relações de poder e subordinação das mulheres em relação aos homens em todas as esferas institucionais da economia incluindo o mercado, o lar, a associação e o Estado; também, nas propostas políticas de transformação dessas estruturas. Em contraste, o ensaio enfatizou as relações equitativas entre os parceiros de trabalho e menos as relações equitativas entre homens e mulheres.

Especificamente, o conceito maximalista de Economia Solidária dificulta a análise das relações de poder e subordinação por razões de gênero e geração nos domicílios, comunidades, associações, cooperativas e nas diversas iniciativas econômicas que buscam caminhar para a economia solidária. Observa-se também que o princípio da equidade de gênero e o lar como espaço institucional ainda não adquiriram o mesmo grau de importância nos diversos aspectos da redação. Por tudo isso, abordar a equidade de gênero é um desafio emergente na literatura da economia social e solidária.

\section{Conclusĩo}

Os desafios do campo de estudo da Economia Social e Solidária são complexos e multidimensionais devido à sua inscrição na tradição das ciências sociais que se propõe a articular o discurso político e o discurso acadêmico. Duas tensões epistemológicas perpassam a construção do objeto de estudo. O primeiro refere-se à relação entre o discurso acadêmico e o discurso político e o segundo à definição a priori do comportamento dos atores econômicos. A primeira tensão

Infantil y licencias Parentales, (12), 4-9, 2011. TILLY, L.; SCOTT J. Women, work and family. New York: Hold, Rinehart and Winston, 1978.

25 A economia feminista trouxe críticas radicais ao conceito de economia na teoria neoclássica para a questão: i) sua visão restrita ao circuito comercial e à invisibilidade da esfera reprodutiva e cuidado como parte da economia; ii) a confusão entre o mercado e a utopia do mercado livre e auto-regulação que nega a importância de quadros normativos, papéis sociais e práticas de poder e discriminação em mercados específicos; iii) o conceito de trabalho limitado a atividades remunerado e não reconhecimento da contribuição social e econômica das atividades não remuneradas para a reprodução da vida social; iv) a noção dominante de modelo de família única; v) a divisão das esferas pública e privada; vi) a suposição de uma racionalidade instrumental - Homo economicus - como o único comportamento adequado para o bom funcionamento da economia. FARAH, I.; WANDERLEY, F. "El feminismo y la otra economía. Una mirada desde América Latina". In Coraggio, J. L. (org.). Economía social y solidaria en movimento. Buenos Aires: Editora Universidad Nacional de General Sarmiento, 2016, p 125-140. 
enfrenta o desafio de articular, sem violar, dois compromissos: o primeiro com a especificidade do saber das ciências sociais - ou seja, o respeito às regras de construção desse tipo de conhecimento - e o segundo com as lutas populares e emancipatórias. Esse desafio é inter-relacionar as duas esferas - acadêmica e política - e, ao mesmo tempo, não subordinar uma à outra.

A segunda tensão enfrenta o desafio de superar a definição do Homo economicus utilitarista sem cair na definição do Homo sociologicus solidarius na construção do objeto de estudo. No contexto do domínio do quadro cognitivo utilitário, os estudos sociológicos e antropológicos da economia enfrentaram - e continuam a enfrentar - o desafio de contrariar a lógica economicista evitando as armadilhas armadas pelo "fantasma" do Homo economicus que assombra a nossa imaginação: a tentação de cair em idealizações que apenas invertem a lógica econômica que queremos evitar; ou seja, o impulso de buscar em grupos ou setores sociais o Homo solidarius em oposição ao homo egoísta e utilitarista, esquecendo que ambos são construções abstratas e essencialistas que não dão conta da complexidade do comportamento humano.

No quadro do paradigma relacional, encontramos o conceito maximalista de economia solidária problemático na definição do objeto de estudo, uma vez que inclui o pressuposto de um puro Homo economicus solidarius que dificulta a análise de comportamentos híbridos e em contínua transformação. A opção por uma concepção minimalista das unidades que compõem a economia solidária pressupõe que as identidades dos atores não sejam únicas nem coerentes internamente em todas as áreas e circunstâncias de suas vidas. Ao contrário, dependem das interações em que se encontram, uma vez que as expectativas mútuas são criadas em processos contínuos que incluem estruturas cognitivas, modelos de associação, sentidos de pertencimento e de lutas ou disputas de controle e poder. Ou seja, os horizontes dos atores só podem ser identificados por pesquisas empíricas voltadas para a compreensão dos processos por meio dos quais os comportamentos econômicos vêm a se instituir.

Em conclusão, consideramos que a definição minimalista das unidades econômicas que integram a Economia Solidária a partir de critérios mais específicos quanto à sua forma de organização, como, por exemplo, o carácter coletivo, a autogestão e a articulação entre objetivos sociais e econômicos no quadro do relacionismo metodológico, é o mais adequado na análise acadêmica. Já a definição maximalista de unidades econômicas com base em princípios morais que fundamentam sua organização e prática, como igualdade, solidariedade e proteção ambiental, é mais adequada no campo político. 


\section{REFERÊNCIAS BIBLIOGRÁFICAS}

ABOFALIA, M. Making markets: Opportunism and restraint on Wall Street. Cambridge: Harvard University Press, 1996.

AGUIRRE, R. "Trabajar y tener hijos: insumos para repensar las responsabilidades familiares y sociales". in M. L. Gutiérrez, M. L. (org.) Género, familias y trabajo: rupturas y continuidades. Desafíos para la investigación política. Buenos Aires: Clacso, 2007, pp. 99-135.

ANDERSEN, J. "El sueño de la casa sin cocina”. in Guzmán, V.; Portocarrero, P.; Vargas, V. (org.). Una nueva lectura: género en el desarrollo. Lima: Flora Tristán, 1991, p. 159-190.

ARRIAGADA, I. Futuro de las familias y desafíos para las políticas. Santiago: CEPAL, 2008.

AXELROD, R. La evolución de la cooperación: el dilema del prisionero y la teoría de juegos. Madrid: Alianza Editorial, 1984.

BAGNASCO, A.; SABEL, C. F. Small and médium size enterprises. London: Pinter, 1995.

BAKER, W. E. "The social structure of a national security market". American Journal of Sociology, 89(4), 775-811, 1984.

BENERÍA, L.; ROLDÁN, M. The crossroads of class and gender. Industrial homework, subcontracting and household dynamics in Mexico City. Chicago: University of Chicago Press, 1987.

BLAU, F. D.; FERBER, M. A.; WINKLER, A. E. The Economics of momen, men and work. New Jersey: Prentice Hall, 1986.

BORDERÍAS, C.; CARRASCO C. Las mujeres y el trabajo. Rupturas conceptuales. Madrid: Economía Crítica, 1994.

BOSERUP, E. Woman's Role in Economic Development. New York: Allen \& Unwin, 1970.

BOURDIEU, P. Las estructuras sociales de la economía. Buenos Aires: Manantial, 2000.

BOURDIEU, P. "Principles of Economic Anthropology”. In Smelser, N.; Swedberg, R. (orgs.). The Handbook of Economic Sociology. New York: Sage, 2005, pp. 75-89.

BURAWOY, M. "2004 Presidential address For Public Sociology”. American Sociological Review, (70), 4-28, 2005.

BURT, R. Structural holes. The Social Structure of Competition. Cambridge: Harvard University Press, 1992.

CATTANI, A. D.; LAVILLE, J.-L.; GAIGER, L. I.; HESPAMHA P. Dicionário Internacional Outra Economia. Coimbra: Almedina, 2009.

CORAGGIO, J. L. "La economía social y solidaria: hacia la búsqueda de posibles convergencias con el Vivir Bien". in Farah, I.; Tejerina, V. (orgs.) Vivir Bien: Infancia, género y economía. Entre la teoría y la práctica. La Paz: Plural Editores, 2013, p 215-256.

DEFOURNY, J. Y; NYSSENS, M. El enfoque emes de empresa social desde una perspectiva comparada. CIRIEC España - Revista de Economía Pública, Social y Cooperativa, (75)7, 2012.

DOBBING, F. Forging Industrial Policy: The United States, Britain, and France in the Railway Age. Cambridge: Cambridge University Press, 1997.

EVANS, P. Embedded Autonomy: States and industrial transformation. Princeton: Princeton University Press, 1995. 
FARAH, I.; WANDERLEY, F. "El feminismo y la otra economía. Una mirada desde América Latina". In Coraggio, J. L. (org.). Economía social y solidaria en movimento. Buenos Aires: Editora Universidad Nacional de General Sarmiento, 2016, p 125-140.

FLIGSTEIN, N. The architecture of markets. An Economic Sociology of twenty-first-century capitalist societies. Princeton: Princenton University Press, 2001.

GAIGER, L. I. "Empreendimento Econômico Solidário". in Cattani, A. D.; Laville, J-L.; Gaiger L. I.; Hespanha, P. (orgs.). Dicionário Internacional Outra Economia. Coimbra: Almedina, 2009, p. 181-187.

GRANOVETTER, M. "Economic Action and Social Structure: The Problem of Embeddedness". in Granovetter, M.; Swedberg, R. (org.). The Sociology of Economic Life. Boulder: Westview Press, 1992, p. 53-84.

HILLENKAMP, I.; LAVILLE, J.-L. et al. Theory of the social enterprise and pluralism. The model of solidarity enterprise. Artigo apresentado no ICSEM MEETING. Bruxelas, 2013.

ICAZA, A. M. S.; TIRIBA, L. (2009). "Economia popular”. in Cattani, A. D.; Laville, J-L.; Gaiger L. I.; Hespanha, P. (orgs.). Dicionário Internacional Outra Economia. Coimbra: Almedina, 2009, p. 150-155.

JELIN, E. Pan y afectos. La transformación de las famílias. Cidade do México: Unam, 2000.

KABEER, N. Realidades trastocadas. Las jerarquías de género en el pensamiento del desarrollo. Cidade do México: Paidós, 1998.

KNORR CETINA, K. "How are global market global? The architecture of a flow world". in Knorr Cetina, K. Preda, A. (orgs.). The Sociology of Financial Markets. Oxford: Oxford University Press, 2005, p. 38-61.

LAVILLE, J.-L.; GAIGER, L. I. "Economia Solidária”. in Cattani, A. D.; Laville, J-L.; Gaiger L. I.; Hespanha, P. (orgs.). Dicionário Internacional Outra Economia. Coimbra: Almedina, 2009, p. 162-168.

NUN, J. "Superpoblación relativa, ejército industrial de reserva y masa marginal". Revista latinoamericana de Sociología, (5)2, 1969.

OSTROM, E.; AHN, T. K. "Una perspectiva de capital social en las ciencias sociales: capital social y acción colectiva". Revista Mexicana de Sociología, 65(1), 155-233, 2003.

PAUTASSI, L.; RICO, M. N. "Licencias para el cuidado infantil. Derechos de hijos, padres y madres". Revista Desafíos. Cuidado Infantil y licencias Parentales, (12), 4-9, 2011.

POLANYI, K. "The economy as instituted process". in Granovetter, M. Swedberg, R. (org.). The sociology of economic life. Westview: Westview Press, 1992, p 29-52.

QUIJANO, O. A. "The Marginal Role of the Economy and the Marginal Labor Force". Economy and Society, 3(4), 393-428, 1974.

QUIJANO, O. A. "Sistemas alternativos de produção?" in Santos, B. S. (org.). Produzir para viver. Os caminhos da produção não capitalista. Porto: Afrontamento, 2003, p. 407-435

RAZETO, L. Los caminos de la economía de solidaridad. Buenos Aires: Lumen-Humanitas, 1996.

SANTOS, B. S. Produzir para viver. Os caminhos da produção não capitalista. Porto: Afrontamento, 2003.

SARAVÍ, G. Entre la comunidad y la autosuficiencia. Cooperación y competencia en un distrito industrial en México. Nueva Antropología, 16(55), 69-87, 1999. 
SINGER, P. "Economía solidaria. Un modo de producción y distribución”. in Coraggio, J-L (org.) La Economía Social desde la periferia. Contribuciones latinoamericanas. Buenos Aires: Altamira, 2007, p. 59-78.

SOMERS, M. "Citizenship and the Place of the Public Sphere: Law, Community, and Political Culture in the Transition to Democracy". Social Science History, 16(4), 1993.

TILLY, L.; SCOTT J. Women, work and family. New York: Hold, Rinehart and Winston, 1978.

TURCHI, L. M.; NOROÑA, E. G. Cooperação e conflito: um estudo de caso do complexo coureiro-calçadista no Brasil. Texto de discussão n. ${ }^{\circ}$ 861. Rio de Janeiro: IPEA, 2002.

VEGA UGALDE, S. "La economía solidaria en el Ecuador de la Revolución ciudadana: Certezas e interrogantes". Opción Socialista, 3, 50-51, 2014.

WANDERLEY, F. Solidarity without cooperation. Small producer networks and political identity in Bolivia. (Tese de Doutorado em Ciências Sociais). Columbia University, 2004.

WANDERLEY, F. Desafíos teóricos y políticos de la economía social y solidaria. Lectura desde América Latina. Bogotá: CIDES-UMSA, 2015.

WHITE, H. "Social Networks can Resolve Actor Paradoxes in Economics and in Psychology". Journal of Institutional and Theoretical Economics, 151(1), 58-74, 1995.

WHITE, H. Markets from networks: socioeconomic models of productions. Princeton: Princeton University Press, 2002.

ZELIZER, V. The social meaning of money. New York: Basic Books, 1997.

ZUCKER, L. G. "Production of Trust: Institutional sources of economic structure, 1840-1920". Research in Organizational Behavior, 8, 1986. 